\section{Commentary: Caution: Falling case volumes}

\author{
Frederick A. Tibayan, MD
}

The response of our health care systems to manage the coronavirus 2019 (COVID-19) pandemic has necessitated a dramatic decrease in elective clinical activity, and consequently, cardiothoracic surgery case volumes. On top of this, as reported in a worldwide survey of cardiothoracic surgery training programs, many resident physicians are either directed to stay home or relocate to wards or intensive care units on the front line of an outbreak. ${ }^{1}$ This combination of factors drives concerns about some cardiothoracic surgery residents meeting minimum case volumes required for graduation ${ }^{2}$ as well as reaching the expected levels of autonomy and expertise for starting their careers. Residents, surgery programs, and employers would all benefit from early identification and intervention in scenarios where COVID-19 may significantly influence the training experience. Boskovski and colleagues ${ }^{3}$ present a theoretical framework for recognizing which residents are most negatively affected in terms of readiness for graduation. The authors include the overall influence of COVID-19 on the institution, baseline case volume, seniority of the trainee, concordance of the trainee's rotations and career track during the outbreak, and nonoperative components. Such a schema may prove useful for not only this pandemic, but also the inevitable outbreaks of the future, and will be informative for those both training and hiring young surgeons. For these at-risk residents, Boskovski and colleagues ${ }^{3}$ propose excellent strategies in use at their own institutions, such as critical review of operative videos, case-based discussions using online meeting tools, double-scrubbing

From the Division of Cardiothoracic Surgery, Department of Surgery, Oregon Health and Science University, Portland, Ore.

Disclosures: The author reported no conflicts of interest.

The Journal policy requires editors and reviewers to disclose conflicts of interest and to decline handling or reviewing manuscripts for which they may have a conflict of interest. The editors and reviewers of this article have no conflicts of interest.

Received for publication July 4, 2020; revisions received July 4, 2020; accepted for publication July 6, 2020; available ahead of print July 11, 2020.

Address for reprints: Frederick A. Tibayan, MD, Division of Cardiothoracic Surgery, Department of Surgery, Oregon Health and Science University, 3181 SW Sam Jackson Park Rd, Mail Code L353, Portland, OR 97239 (E-mail: tibayan@ohsu. edu).

J Thorac Cardiovasc Surg 2020;160:1130-1

0022-5223/ $\$ 36.00$

Copyright $₫ 2020$ Published by Elsevier Inc. on behalf of The American Association for Thoracic Surgery

http://dx.doi.org/10.1016/j.jtcvs.2020.07.012

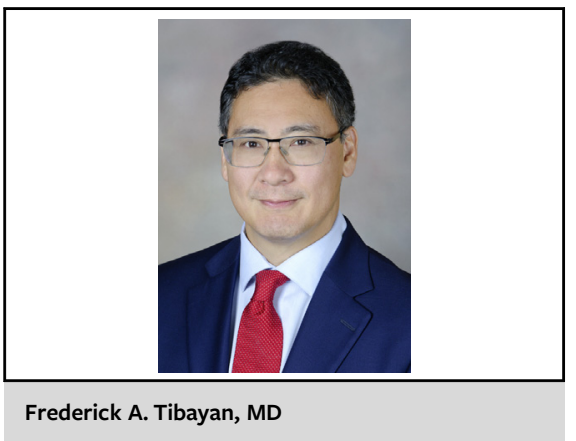

CENTRAL MESSAGE

Adequate training during the

COVID-19 pandemic requires

early identification of obstacles.

To meet minimum requirements,

residents will need innovative

educational strategies and

directed mentorship.

with junior residents, and increased mentorship from surgical educators and senior partners.

Simple predictive models such as this have demonstrated great potential for robustness and broad applicability. ${ }^{4}$ However, the framework and solutions as described are most relevant for an outbreak of relatively limited duration. In regions where the burden of the pandemic is steady or increasing for extended and uncertain time periods, longterm curriculum changes for both junior and senior trainees may be required. The authors' noting of the effects of the COVID-19 pandemic on the health and family life of trainees who may have to care for sick parents or facilitate remote learning for school-aged children deserves special mention. These factors represent important aspects of the physical and emotional well-being of trainees as well as their ability to learn effectively. Everything may seem different during the pandemic, but cardiothoracic surgeons in training need flexible, compassionate education, and dedicated mentorship. That will always be a constant in our field.

\section{References}

1. Gaudino M, Chikwe J, Hameed I, Robinson NB, Fremes SE, Ruel M. Response of cardiac surgery units to COVID-19: an internationally-based quantitative survey. Circulation. May 11, 2020 [Epub ahead of print].

2. Vaporciyan AA. The changing roles and responsibilities of program directors during the COVID crisis. Virtual presentation at: Cardiothoracic 
Surgery in the COVID Crisis: Impact on Residency and Training; May 7, 2020.

3. Boskovski MT, Hirji SA, Brescia AA, Chang AC, Kaneko T. Enhancing thoracic surgical trainee competence in the COVID-19 era: challenges and opportunities for mentorship. J Thorac Cardiovasc Surg. 2020;160: 1126-9.

4. Dawes R. The robust beauty of improper linear models in decision making. Am Psychol. 1979;34:571-82.
See Article page 1126.

\section{Commentary: Mentoring trainees when the going gets tough}

Mara B. Antonoff, MD

In their Expert Opinion, Boskovski and colleagues ${ }^{1}$ discuss ways to enhance thoracic surgical trainee competence during the coronavirus 2019 (COVID-19) era. ${ }^{1}$ As has been elaborated by previous authors, this pandemic has changed not only the ways that we live, work, and socialize it has also changed the ways that we, as academic cardiothoracic surgeons, engage in education. ${ }^{2}$ We have entered a time in which we must adapt to the needs of our trainees by developing innovative, collaborative curricular strategies, which carry the potential to improve the efficiency, versatility, and quality of trainees' education long after the pandemic has ended. ${ }^{2,3}$

Boskovski and colleagues ${ }^{1}$ have developed a conceptual framework for quantifying the educational impact of the pandemic on trainees, highlighting the key areas of the COVID-19 burden within the training institution, program case volumes, resident level of training, rotations assigned during the pandemic, and external factors that may impact one's learning. They have reviewed ways to use mentorship to mitigate the negative effects of the pandemic on the future surgeons of our specialty, ranging from junior-level trainees to early-career surgeons. Their proposed ideas include a breadth of

\footnotetext{
From the Department of Thoracic and Cardiovascular Surgery, The University of Texas MD Anderson Cancer Center, Houston, Tex.

Disclosures: The author reported no conflicts of interest.

The Journal policy requires editors and reviewers to disclose conflicts of interest and to decline handling or reviewing manuscripts for which they may have a conflict of interest. The editors and reviewers of this article have no conflicts of interest.

Received for publication June 30, 2020; revisions received June 30, 2020; accepted for publication June 30, 2020; available ahead of print July 13, 2020.

Address for reprints: Mara B. Antonoff, MD, Department of Thoracic and Cardiovascular Surgery, University of Texas MD Anderson Cancer Center, 1515 Holcombe Blvd, Houston, TX 77030 (E-mail: MBAntonoff@mdanderson.org).

J Thorac Cardiovasc Surg 2020;160:1131-2

0022-5223/\$36.00

Copyright (c) 2020 by The American Association for Thoracic Surgery

http://dx.doi.org/10.1016/j.jtcvs.2020.06.112
}

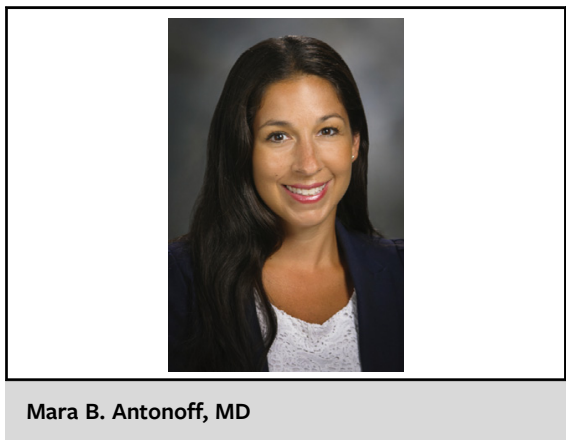

CENTRAL MESSAGE

Mentorship is key to supporting trainees through the curricular challenges of a pandemic; more importantly, mentorship is crucial to navigating heightened external challenges during this time.

approaches such as teaching decision making via telehealth, promoting academic success through remote research opportunities, and using simulation to enhance technical skills. This article focuses expertly in these areas; nevertheless, it is critical that we stay simultaneously attuned to the fact that there are additional areas of mentoring needs for our trainees during this crisis.

As we consider the impact of the pandemic on a training environment and its ability to enable acquisition of knowledge and technical skills by trainees, it is clearly enormous. ${ }^{2}$ Such in-hospital issues may pale, however, compared with those that occur outside of the training environment-yet still impact training. These additional influences on trainees' ability to learn during the pandemic include the trainees' personal health, whether they have been out of work (either ill with COVID-19 or quarantining due to exposure or family illness), and the detrimental influence of family needs on time to study at home. Moreover, and perhaps even of greater importance, is the fact that trainees may also be balancing direct these educational issues with finding food for one's family, caring for aging parents, 